\title{
Role of Hydroxycinnamic Acids in the Infection of Maize Silks by Fusarium graminearum Schwabe
}

\author{
Ana Cao, ${ }^{1}$ Lana M. Reid, ${ }^{2}$ Ana Butrón, ${ }^{1}$ Rosa Ana Malvar, ${ }^{1}$ Xose C. Souto, ${ }^{3}$ and Rogelio Santiago ${ }^{1}$ \\ ${ }^{1}$ Misión Biológica de Galicia, Spanish Council for Scientific Research (CSIC), Apartado 28, E-36080, Pontevedra, Spain; \\ ${ }^{2}$ Eastern Cereal and Oilseed Research Centre, Agriculture and Agri-Food Canada. Central Experimental Farm, Building 99, \\ Ottawa, Ontario, K1A0C6, Canada; ${ }^{3}$ E.U.E.T. Forestal, Universidad de Vigo. Campus Universitario Pontevedra, E- 36005, \\ Pontevedra, Spain
}

Submitted 30 March 2011. Accepted 13 May 2011.

In the current study, the hydroxycinnamic acids in silks of diverse maize inbred lines differing in Fusarium resistance were determined at several times after inoculation with Fusarium graminearum or sterile water as control. The main objective was to determine the possible relationship between the hydroxycinnamic acid changes in silks and ear rot resistance. Several changes in the cell-wall-bound hydroxycinnamic acid concentrations were observed after inoculation with $F$. graminearum, although these changes were not directly correlated with genotypic resistance to this fungus. Ester-bound ferulic acid decreased, probably due to degradation of hemicellulose by hydrolytic enzymes produced by Fusarium spp., while $p$-coumaric acid and diferulates showed slight increases that, in conjunction, did not result in delayed $F$. graminearum progression through the silks. It is important to note that the decrease of ferulic acid in the $F$. graminearum treatment was faster in susceptible than in resistant genotypes, suggesting a differential hemicellulose degradation in silk tissues. Therefore, the ability of the maize genotypes to slow down that process through hemicellulose structural features or xylanase inhibitors needs to be addressed in future studies.

Fusarium graminearum Schwabe (sexual stage Gibberella zeae (Schwein.) Petch) is one of the most important plant pathogens infecting several cereal species including maize, wheat, and barley, in temperate regions (Logrieco et al. 2003; Munkvold 2003; Sutton 1982). In maize (Zea mays L.), both the ear and the stalk can be infected (Logrieco et al. 2003; Sutton 1982). Ear rot by $F$. graminearum is a sporadic disease (Sutton 1982) but of major economic importance because this fungus contaminates the grain with mycotoxins (Logrieco et al. 2003, Pestka 2007). Zearalenone and trichothecenes type B toxins such as deoxynivalenol (DON) and its derivates are produced by $F$. graminearum and can result in several disorders and diseases in animals and humans (Logrieco et al. 2002; Pestka 2007).

In maize fields, $F$. graminearum is dispersed from the soil and crop debris in the form of macroconidia, ascospores, and hyphal fragments by wind, splashing water, or insect vectors (Munkvold 2003; Sutton 1982). Entry into the ear is primarily via the exposed silks but can also occur through kernel wounds created by insects, birds, and hail (Koehler 1942; Munkvold 2003). Consequently, infection generally starts in the ear tip and spreads down toward the butt of the cob. Symptoms include

Corresponding author: A. Cao; E-mail: anacao@mbg.csic.es the development of a pink or red mycelium on the kernels. In the most severe cases, infection reaches the husks and rachis (Munkvold 2003; Sutton 1982).

Genotypic differences in resistance have been identified after artificial inoculation of Fusarium macroconidia into the silk channel of maize inbreds (Reid et al. 1992c). Miller and associates (2007) followed the progress of $F$. graminearum mycelium down the silks toward the developing kernels and rachis; they observed mycelial growth on the silk surface and inside the epidermal cells of the silk from the second and third days, respectively, after macroconidia attachment. The time it took for mycelium to reach the kernels was different in resistant and susceptible genotypes, suggesting the existence of resistance mechanisms in the silks (Miller et al. 2007).

Maize silk infection and development of $F$. gramineraum in silk tissues are believed to be influenced by morphological factors such as husk coverage, physiological factors such as flowering time and silk age, and diverse biochemical factors (Logrieco et al. 2003; Reid et al. 1992a; Sutton 1982). Attending to the last point, changes in silk flavone content were observed after artificial infection with $F$. graminearum (Reid et al. 1992b) but no association between flavone content and resistance was established. Similarly, genotypic differences in the alkane contents of silk wax did not satisfactorily explain differences in resistance to F. graminearum (Miller et al. 2003).

In order to investigate the role of some other compounds in Fusarium resistance, in the present study, we focused our attention toward the hydroxycinnamic acid contents. Several studies have reported the ability of low molecular weight phenolics, such as hydroxycinnamic acids, to inhibit Fusarium spp. growth (Assabgui et al. 1993; Kasenberg and Traquair 1988; McKeehen et al. 1999; Samapundo et al. 2007) and mycotoxin production (Bakan et al. 2003; Beekrum et al. 2003; Boutigny et al. 2009). In addition, the role of hydroxycinnamic acids as central factors for cell wall fortification could be decisive to difficult pathogen invasion. In this sense, an increase in cell-wall-bound phenolic compounds has been observed in roots and stems after fungal inoculation or elicitation in several crops (de Ascensao and Dubery 2003; El Modafar et al. 2000; Santiago et al. 2009). Particularly in maize, structural hydroxycinnamic acids have been associated with resistance to Fusarium disease in kernel and stalk pith tissues (Assabgui et al. 1993; Bily et al. 2003; Santiago et al. 2007). However, no studies to date have investigated the role of induced or constitutive hydroxycinnamic acids of the silk tissues in $F$. graminearum resistance. In view of the fact that silks are where the initial fungal development takes place and represent a key infection pathway to the ear, evaluation of hydroxycinnamic 
acid contents and Fusarium spp. development on silk tissues is of significant interest.

In the current study, the hydroxycinnamic acids in silks of diverse maize inbred lines differing in Fusarium resistance were determined at several times after inoculation with $F$. graminearum or sterile water as control. The specific objectives were to i) observe whether changes in hydroxycinnamic acid concentrations occur as silks age, ii) determine whether any changes are influenced by infection with $F$. graminearum, and iii) determine the possible relationship between the hydroxycinnamic acid response in silks and ear rot resistance.

\section{RESULTS}

\section{Disease severity ratings and ergosterol concentration after inoculation.}

Ears from four Agriculture and Agri-Food Canada (AAFC) maize inbred lines were evaluated at grain harvest for $F$. graminearum ear rot severity. Disease severity was evaluated using a visual scale based on the percentage of kernels with visible symptoms (discussed below). Disease ratings in the $F$. graminearum treatment separated the inbreds into two statistically significant groups: CO266 and CO272, with higher ear rot ratings (6.15 and 5.38, respectively), and CO433 and CO441, with lower ratings (2.76 and 2.77, respectively) (Table 1). These ratings concur with previous studies; however, CO272 is exhibiting more susceptibility than when it was first used many years ago as a source of resistance (Reid et al. 1992c).

In order to characterize the growth of the fungus on the different genotypes, ergosterol from silk tissues was measured at five harvest times $(0,2,6,10$, and 14 days after inoculation) in the $F$. graminearum treatment. At 0 days, none or very low ergosterol was detected whereas, as expected, ergosterol contents increased with time as the mycelia grew (Table 1). Fungal growth was faster and ergosterol concentrations were higher in silks from the more susceptible inbreds CO266 and CO272 (from 0.00 to 334.00 and $342.04 \mu \mathrm{g} / \mathrm{g}$, respectively), whereas ergosterol increased more slowly and was lower in silks from CO433 and CO441 (from 0.00 and 0.23 to 161.90 and $211.49 \mu \mathrm{g} / \mathrm{g}$, respectively).

\section{Changes in hydroxycinnamic acid concentration after inoculation.}

Both soluble and cell-wall-linked hydroxycinnamic acids were extracted from silk tissues recollected at $0,2,6,10$, and 14 days after inoculation with $F$. graminearum inoculum or sterile water. Only trace amounts of soluble hydroxycinnamic acids were found in silks at all harvest times and in all genotypes; no quantification was done. The main hydroxycinnamic acids linked to the cell wall were monomers of ferulic acid (FA) and $p$-coumaric acid (PCA) and dimers of ferulic acid (DFA), as shown in Table 2. Four different DFA were identi- fied and quantified: 5-5' DFA, 8-5' DFA (sum of 8-5'-noncyclic and 8-5'-benzofuran forms), and 8-0-4' DFA. DFA's role in resistance was based in the total content (DFAT) generally related to cell-wall strengthening (Bunzel 2010). FA was the most prevalent phenol in cell walls of the silk tissues at all harvest times and for both treatments. PCA levels found in silk tissues were much lower than FA levels in both treatments, in accordance with previous studies made with the grain pericarp (Bily et al. 2003). Concentrations of DFAT (sum of the isomers) in the silk tissues, regardless of the treatment, were higher than quantities found in other tissues (Barros-Ríos et al. 2011; Santiago et al. 2006a and b).

In the sterile water treatment, the highest contents of FA at 0 days were quantified in the inbred lines CO441, CO433, and $\mathrm{CO} 272$ (from $5,789.7$ to $5,133.2 \mu \mathrm{g} / \mathrm{g}$ ) and the lowest content in the inbred line CO266 (3,965.3 $\mathrm{\mu g} / \mathrm{g}$ ) (Table 2). Differences were not significant at 14 days after inoculation. FA concentrations increased with time in all genotypes, although the increment was not significant for the inbred line CO441. Similarly, in the $F$. graminearum treatment, the highest contents of $\mathrm{FA}$ at 0 days were found in $\mathrm{CO} 441, \mathrm{CO} 433$, and $\mathrm{CO} 272$ (from $5,744.9$ to $5,144.2 \mu \mathrm{g} / \mathrm{g})$ and the lowest in CO266 $(4,142.9$ $\mu \mathrm{g} / \mathrm{g}$ ). Only one inbred, CO272, showed a statistically significant change in FA concentrations over time, with FA decreasing after 6 days (Table 2). A similar trend was observed in CO266, in which FA tended to decrease after 2 days, and in CO443 and CO441 after 10 days. These decreases in FA occurred at the same time that the silk ergosterol content exceeded $100 \mu \mathrm{g} / \mathrm{g}$ in each inbred (Tables 1 and 2).

In both treatments, PCA concentrations increased slightly with time for all genotypes, with the exception of the water treatment for $\mathrm{CO} 272$ and $\mathrm{CO} 433$, which exhibited no significant difference over time (Table 2). CO272 had significantly lower PCA concentrations than the other genotypes in the water treatment whereas, in the $F$. graminearum treatment, $\mathrm{CO} 272$ had the highest PCA concentrations until day 6, after which significant differences between inbred lines were not apparent in the Fusarium treatment.

DFAT concentrations increased with time in all genotypes and in both treatments (Table 2). CO266 tended to reach the highest DFAT content starting at 2 days in the water treatment. In the Fusarium treatment, results were similar but differences between genotypes were not significant at 2, 10, and 14 days. With respect to the DFA isomers, 8-5' DFA was the most abundant in all genotypes (50 to $60 \%$ of DFAT), followed by 8-o-4' DFA (25 to $30 \%$ ) and, last, by $5-5^{\prime}$ DFA (15 to $20 \%$ ) in both treatments (data not shown).

Differences between treatments for FA concentration were significant for the inbred line $\mathrm{CO} 433$ at 6 days, inbred lines $\mathrm{CO} 272$ and $\mathrm{CO} 441$ at 10 days, and inbred lines CO266, $\mathrm{CO} 272$, and $\mathrm{CO} 433$ at 14 days (Table 2). In all cases, higher concentrations of FA were found in the water treatment. The

Table 1. Disease severity ratings (DSR) at grain harvest for four maize inbred lines (IL) silk channel inoculated with Fusarium graminearum macroconidia or sterile water (Control); and ergosterol contents in the silk tissues at five harvest times after inoculation with F. graminearum, in 2007 and $2008^{\mathrm{y}}$

\begin{tabular}{|c|c|c|c|c|c|c|c|c|c|c|}
\hline \multirow[b]{2}{*}{ IL } & \multirow[b]{2}{*}{ Pedigree } & \multicolumn{2}{|c|}{ DSR per treatment ${ }^{\mathrm{Z}}$} & \multicolumn{6}{|c|}{ Ergosterol contents ( $\mu \mathrm{g} / \mathrm{g}$ dry weight) at harvest times (days) } & \multirow[b]{2}{*}{ Resistance } \\
\hline & & Control & F. graminearum & $\mathbf{0}$ & 2 & 6 & 10 & 14 & $\mathbf{L S D}_{1}$ & \\
\hline $\mathrm{CO} 266$ & Pioneer 3990 & $2.01 \mathrm{a}$ & $6.15 \mathrm{a}$ & $0.00 \mathrm{a}$ & $3.76 \mathrm{a}$ & $102.97 \mathrm{a}$ & $253.26 \mathrm{a}$ & $334.00 \mathrm{a}$ & 79.53 & Susceptible \\
\hline $\mathrm{CO} 272$ & BSTEx(CO109xCO106) CO109 & $1.00 \mathrm{a}$ & $5.38 \mathrm{a}$ & $0.00 \mathrm{a}$ & $4.13 \mathrm{a}$ & $8.97 \mathrm{~b}$ & $159.92 \mathrm{ab}$ & $342.04 \mathrm{a}$ & 87.03 & Susceptible \\
\hline $\mathrm{CO} 433$ & Pride K127 & $1.23 \mathrm{a}$ & $2.76 \mathrm{~b}$ & $0.00 \mathrm{a}$ & $5.35 \mathrm{a}$ & $18.21 \mathrm{~b}$ & $57.60 \mathrm{c}$ & $161.90 \mathrm{~b}$ & 87.53 & Resistant \\
\hline $\mathrm{CO} 441$ & Jacques 7700xCO298 & $2.07 \mathrm{a}$ & $2.77 \mathrm{~b}$ & $0.23 \mathrm{a}$ & $4.37 \mathrm{a}$ & $21.66 \mathrm{~b}$ & $64.45 \mathrm{bc}$ & $211.49 \mathrm{~b}$ & 48.80 & Resistant \\
\hline $\mathrm{LSD}_{2}$ & $\ldots$ & $\ldots$ & 2.12 & $\ldots$ & $\ldots$ & 27.43 & 97.14 & 107.47 & $\ldots$ & $\ldots$ \\
\hline
\end{tabular}

${ }^{y}$ Means within a column followed by the same lowercase letter are not significantly different $(P \leq 0.05)$. Least significant difference $\left(\right.$ LSD) $(P \leq 0.05)$ : LSD ${ }_{1}=$ ergosterol concentration comparison between days, $\mathrm{LSD}_{2}=$ ergosterol concentration and DSR comparisons between inbred lines.

${ }^{\mathrm{z}}$ Disease severity visual rating scale per inoculation treatment was $1=$ no infection and $2=1$ to $3,3=4$ to $10,4=11$ to $25,5=26$ to $50,6=51$ to 75 , and $7=$ $>75 \%$ of the kernels exhibit visible symptoms. 
largest differences in FA contents were quantified in CO266; at 14 days, this inbred had FA at 3,435.6 $\mu \mathrm{g} / \mathrm{g}$ less than in the water treatment $(6,171.7 \mu \mathrm{g} / \mathrm{g})$. In contrast, PCA and DFAT levels tended to be higher in the $F$. graminearum treatment than in the water treatment. CO266 showed significantly higher levels of PCA in the $F$. graminearum treatment at 6 days $(234.4 \mu \mathrm{g} / \mathrm{g})$ while inbred line CO272 had significantly higher concentrations of PCA from 6 to 14 days (271.4 to $350.0 \mu \mathrm{g} / \mathrm{g}$ ). No significant differences between treatments for PCA were found in the inbred lines CO433 and CO441. DFAT contents were significantly higher in the $F$. graminearum treatment in $\mathrm{CO} 272$ at 6 and 14 days, in CO433 at 14 days, and in CO441 at 2 days (Table 2).

\section{DISCUSSION}

Significant differences existed among four maize inbreds for both the occurrence of $F$. graminearum in the silks as meas- ured by ergosterol and final ear rot severity ratings on the kernels. The inbreds could be classified in two groups: CO266 and $\mathrm{CO} 272$ as susceptible (quick fungal development in silks with abundant visible kernel disease symptoms) and CO433 and $\mathrm{CO} 441$ as resistant (slow fungal development and lower ear rot symptoms). This suggests that a faster development of the fungus on silk tissue would result in higher ratings of visual symptoms on the ear. However, it should be considered that resistance mechanisms could exist in the kernel when they are not present in the silk, or vice versa.

In a search for possible mechanisms of silk resistance, we focused on hydroxycinnamic acids because of their structural properties in planta, their antibiotic effects in vitro (Assabgui et al. 1993; Ishii 1997), and their role in resistance to pests and diseases (Bily et al. 2003; Santiago and Malvar 2010; Santiago et al. 2006a). Only trace amounts of soluble forms of hydroxycinnamic acids were observed in the silk tissues. These results were in agreement with the low contents of soluble hydroxy-

Table 2. Mean concentrations of the cell wall monomers ferulic acid (FA) and p-coumaric acid (PCA) and ferulic acid dimers (DFAT) in silk tissues of four inbred lines (IL) at five harvest times after inoculation with Fusarium graminearum macroconidia or sterile water in 2007 and $2008^{\mathrm{x}}$

\begin{tabular}{|c|c|c|c|c|c|c|c|}
\hline \multirow[b]{2}{*}{ Compound, $\mathrm{IL}^{\mathrm{y}}$} & \multirow[b]{2}{*}{ Treatment $^{\mathrm{z}}$} & \multicolumn{5}{|c|}{ Concentrations ( $\mu \mathrm{g} / \mathrm{g}$ dry weight) at harvest times (days) } & \multirow[b]{2}{*}{$\mathbf{L S D}_{1}$} \\
\hline & & $\mathbf{0}$ & 2 & 6 & 10 & 14 & \\
\hline \multicolumn{8}{|l|}{ FA } \\
\hline \multirow[t]{3}{*}{$\mathrm{CO} 266$} & W & $3,965.3$ & $5,506.2$ & $5,951.8$ & $6,304.5$ & $6,171.7$ & 696.2 \\
\hline & $\mathrm{F}$ & $4,142.9$ & $4,224.7$ & $4,121.5$ & $3,177.5$ & $2,736.1$ & $\ldots$ \\
\hline & $\mathrm{LSD}_{2}$ & & & & & $1,498.9$ & \\
\hline \multirow[t]{3}{*}{$\mathrm{CO} 272$} & W & $5,133.2$ & $5,926.2$ & $6,480.4$ & $6,872.5$ & $6,987.5$ & 390.8 \\
\hline & $\mathrm{F}$ & $5,144.2$ & $6,162.7$ & $6,340.0$ & $5,247.9$ & $5,279.8$ & 918.4 \\
\hline & $\mathrm{LSD}_{2}$ & & & & $1,542.6$ & 688.9 & \\
\hline \multirow{3}{*}{$\mathrm{CO} 433$} & W & $5,789.7$ & $6,161.2$ & $7,001.0$ & $6,933.8$ & $7,238.3$ & 457.7 \\
\hline & $\mathrm{F}$ & $5,744.9$ & $5,582.9$ & $5,908.9$ & $6,172.5$ & $5,351.3$ & $\ldots$ \\
\hline & $\mathrm{LSD}_{2}$ & & & 505.4 & & 993.1 & $\ldots$ \\
\hline \multirow[t]{3}{*}{$\mathrm{CO} 441$} & W & $5,291.0$ & $5,990.0$ & $6,505.2$ & $7,450.8$ & $7,738.1$ & $\ldots$ \\
\hline & $\mathrm{F}$ & $5,385.5$ & $5,957.2$ & $5,707.0$ & $6,294.6$ & $5,823.6$ & $\ldots$ \\
\hline & $\mathrm{LSD}_{2}$ & $\ldots$ & $\ldots$ & & 703.9 & $\ldots$ & $\ldots$ \\
\hline \multirow{2}{*}{$\mathrm{LSD}_{3}$} & W & 858.9 & $\ldots$ & 555.8 & 669.7 & $\ldots$ & $\ldots$ \\
\hline & $\mathrm{F}$ & 723.3 & $\ldots$ & 769.1 & 738.0 & 971.1 & $\ldots$ \\
\hline \multicolumn{8}{|l|}{ PCA } \\
\hline \multirow{3}{*}{$\mathrm{CO} 266$} & W & 120.8 & 135.8 & 144.7 & 205.6 & 248.0 & 35.8 \\
\hline & $\mathrm{F}$ & 135.0 & 142.8 & 234.4 & 227.5 & 202.9 & 76.1 \\
\hline & $\mathrm{LSD}_{2}$ & & & 55.0 & & & $\ldots$ \\
\hline \multirow[t]{3}{*}{$\mathrm{CO} 272$} & W & 192.1 & 185.9 & 182.2 & 154.8 & 143.5 & $\ldots$ \\
\hline & $\mathrm{F}$ & 199.1 & 288.9 & 271.4 & 266.5 & 350.0 & 62.5 \\
\hline & $\mathrm{LSD}_{2}$ & & & 45.8 & 100.0 & 68.7 & $\ldots$ \\
\hline \multirow[t]{3}{*}{$\mathrm{CO} 433$} & W & 100.3 & 113.6 & 167.7 & 205.8 & 227.6 & $\ldots$ \\
\hline & $\mathrm{F}$ & 97.6 & 97.9 & 174.2 & 219.6 & 205.2 & 52.3 \\
\hline & $\mathrm{LSD}_{2}$ & & & & & & \\
\hline \multirow[t]{2}{*}{$\mathrm{CO} 441$} & W & 107.5 & 139.3 & 154.3 & 228.6 & 224.4 & 40.8 \\
\hline & $\mathrm{F}$ & 108.0 & 134.9 & 200.3 & 245.7 & 275.2 & 53.2 \\
\hline \multirow{3}{*}{$\mathrm{LSD}_{3}$} & $\mathrm{LSD}_{2}$ & $\ldots$ & $\ldots$ & $\ldots$ & $\ldots$ & $\ldots$ & $\ldots$ \\
\hline & W & 49.7 & $\ldots$ & $\ldots$ & 44.3 & 48.2 & $\ldots$ \\
\hline & $\mathrm{F}$ & 41.5 & 43.5 & 64.1 & $\ldots$ & $\ldots$ & $\ldots$ \\
\hline \multicolumn{8}{|l|}{ DFAT } \\
\hline \multirow[t]{3}{*}{ CO266 } & W & 205.4 & 456.9 & 666.0 & 741.1 & 998.7 & 273.6 \\
\hline & $\mathrm{F}$ & 183.0 & 361.6 & 804.4 & 850.5 & 965.0 & 308.9 \\
\hline & $\mathrm{LSD}_{2}$ & & & & & & \\
\hline \multirow[t]{3}{*}{$\mathrm{CO} 272$} & W & 74.7 & 157.8 & 317.0 & 554.5 & 673.0 & 137.8 \\
\hline & $\mathrm{F}$ & 67.7 & 368.7 & 510.9 & 689.0 & 919.8 & 204.0 \\
\hline & $\mathrm{LSD}_{2}$ & & & 95.4 & & 178.8 & \\
\hline \multirow[t]{3}{*}{$\mathrm{CO} 433$} & W & 137.7 & 216.0 & 299.1 & 378.8 & 445.1 & 107.9 \\
\hline & $\mathrm{F}$ & 195.8 & 169.4 & 399.5 & 562.8 & 561.1 & 224.2 \\
\hline & $\mathrm{LSD}_{2}$ & & & & & 106.3 & \\
\hline \multirow[t]{2}{*}{$\mathrm{CO} 441$} & W & 152.4 & 244.0 & 390.5 & 619.3 & 811.6 & 371.9 \\
\hline & $\mathrm{F}$ & 174.0 & 360.5 & 458.2 & 646.6 & 801.5 & $\ldots$ \\
\hline \multirow{3}{*}{$\mathrm{LSD}_{3}$} & $\mathrm{LSD}_{2}$ & $\ldots$ & 92.4 & & $\ldots$ & & $\ldots$ \\
\hline & W & 67.8 & 120.3 & 173.7 & $\ldots$ & 169.6 & $\ldots$ \\
\hline & $\mathrm{F}$ & 66.4 & $\ldots$ & 205.1 & $\ldots$ & $\ldots$ & $\ldots$ \\
\hline
\end{tabular}

${ }^{\mathrm{x}}$ Least significant differences (LSD): $\mathrm{LSD}_{1}$, comparisons between days, $\mathrm{LSD}_{2}$, comparisons between treatments, and $\mathrm{LSD}_{3}$, comparisons between inbred lines in each treatment. Significant differences between treatments for a particular inbred line are indicated in bold.

${ }^{y}$ Phenolic compounds and inbred lines.

${ }^{\mathrm{z}}$ Treatments: $\mathrm{W}=$ sterile water treatment, $\mathrm{F}=F$. graminearum treatment. 
cinnamic acids found in pith tissues in a previous study by Santiago and associates (2007). In silk tissues as well as in pith tissues, most hydroxycinnamic acids were found linked to the cell wall via esterification (Santiago et al. 2007).

Cell wall ester-bound FA was the major hydroxycinnamic acid quantified in the silks of the four genotypes. FA is usually esterified to arabinoxylan chains and its incorporation into the cell wall is continuous (Hatfield and Marita 2010). Esterbound forms of FA can be covalently coupled by peroxidases to form dehydroferulate dimers (DFA) that cross-link arabinoxylan chains (Iiyama et al. 1994; Ishii 1997). In addition, FA can be a template for the binding and polymerization of lignin and a lignin union link with hemicellulose chains (Iiyama et al. 1994). FA contents in silks were higher than amounts extracted from pith and, in some cases, from grain tissues even in two of the inbreds used in this study, CO441 and CO433 (Assabgui et al. 2003; Santiago et al. 2007). In silk tissues inoculated with sterile water, FA increased as the silks aged. However, after inoculation with $F$. graminearum, FA began to decrease. This decrease began earlier in susceptible genotypes, at 2 to 6 days after inoculation, than in resistant genotypes, after 10 days. FA decrease under inoculation with $F$. graminearum was accompanied by a significant increase of fungal development as measured by ergosterol content in the silks. Lower concentrations of FA in the cell wall of the inoculated silks could be due to cell wall degradation from fungal attack. Degradation of silk tissues by $F$. graminearum was observed in experiments by Miller and associates (2007) and Reid and associates (1992b). Decrease of cell-wall-linked FA also has been quantified in wheat and barley grains inoculated with $F$. graminearum and $F$. culmorum, in comparison with naturally infected grains (Eggert et al. 2010).

$F$. graminearum secretes a broad array of enzymes during plant infection, among which are xylanases and feruloyl esterases (Walter et al. 2010). FA or FA conjugates could be released from cell walls by the action of feruloyl esterases and xylanases, respectively; these enzymes act synergistically, and the action of xylanases influences the activity of feruloyl esterases (Bartolomé et al. 1995). However, no increase of free FA in silk tissues was observed (data not shown) after cellwall-bound FA decreased, and no fungal growth inhibition was observed as would be expected if free FA increased (Assabgui et al. 1993; McKeehen et al. 1999). Trace amounts of FA in the free soluble fraction, and even in the soluble ester conjugate and glycosilate fractions in the inbred CO266 (data not shown), suggest a complex degradation of FA by the fungus after its release (Nazareth and Mavinkurve 1986; Rosazza et al. 1995).

Degradation of xylan by xylanases are hypothesized to depend on several factors such as the level of branching of arabinoxylan chains, degree of substitutions of xylan backbone, chain cross-linking, or presence of xylanase inhibitors (Beaugrand et al. 2010; Grabber et al.1998; Lagaert et al. 2009). However, simple feruloylation of xylans does not appear to affect maize cell wall degradation by hydrolytic enzymes such as xylanases (Grabber et al. 1998), and important removal of FA has been described after xylanase treatment of wheat bran (Beaugrand et al. 2010). Thus, it appears that constitutive contents of monomeric ester-bound FA in silk cell walls have no role in the resistance to $F$. graminearum cell wall degradation. Recent studies pointed out other substituents of xylan, such as esterbound acetyl groups, limit the xylanase activity in maize cell walls (Agger et al. 2010). Deacetylation of insoluble corn bran was found to promote the enzymatic degradation of hemicellulose, and to a more important degree than deferuloylation (Agger et al. 2010). Moreover, there have been reports in cereals, including maize, of proteinaceous xylanase inhibitors that block fungal xylanases by a competitive inhibitory mechanism (Biely et al. 2008; Lagaert et al. 2009). Thus, hemicellulose degradation and resulting ester-bound FA decreases in silk tissues could be because of $F$. graminearum infection, and the ability of the maize genotypes to slow down that process through structural features or xylanase inhibition could both influence the level of kernel infection.

Concentrations of linked PCA in silk tissues were much lower than FA concentrations. Independent of the treatment, PCA contents increased as the silks aged; however, for the two susceptible inbreds, CO272 and CO266, PCA concentrations increased in the $F$. graminearum treatment when compared with the control, thus suggesting a possible induction by $F$. graminearum. The PCA increases observed in silk, although significant, were minimal, and not enough to affect fungal development. Cell-wall-bound PCA, together with FA, is related to cell wall lignification, and PCA is incorporated into cell walls as part of the lignin fraction linked to monolignols (Hatfield and Marita 2010). An increase in lignin concentrations was observed after Fusarium elicitation in banana (Musa acuminata) root tissues (de Ascensao and Dubery 2003), and an increase in lignin and cell-wall-bound PCA concentrations was also detected after Fusarium inoculation of roots in date palm (Phoenix dactylifera) (El Modafar et al. 2000). The low contents of PCA in silks indicate a minor significance of lignification in these tissues, especially when compared with PCA concentrations in pith cell walls (Santiago et al. 2007). The PCA data, together with higher concentrations of FA and DFAT, suggest that hemicellulose fraction in the silks cell walls is a more significant fraction than lignin.

In cell walls, ferulates could be oxidatively coupled to form dehydrodiferultes, which covalently cross-link polysaccharides chains (Ishii 1997). Dimerization of ester-bound FA monomers in the cell walls of the silk tissues was relatively high in comparison with contents in other maize tissues (Barros-Ríos et al. 2011; Santiago et al. 2006b, 2007). In addition, contents of DFAT showed an increase during sample period for both treatments. Thus, polysaccharide cross-linking was related to an increase of the structural strength and decrease in cell wall extensibility (Kamisaka et al. 1990; Wakabayashi et al. 1997). Increase in DFAT in cell walls over time could be produced naturally by cessation of cell growth. Moreover, silks appear to increase rigidity and to stop elongation after pollination (Sella Kapu and Cosgrove 2010). Polysaccharide cross-linking was also related to cell wall enzyme degradation, because the access of hydrolytic enzymes to the polysaccharides could be reduced (Beaugrand et al. 2010; de O. Buanafina 2009; Grabber et al. 1998). Significant induction of DFAT accumulation has been observed after inoculation with $F$. graminearum but it was punctual and did not have any evident influence on resistance to attack by $F$. graminearum. No relation could be found in silk tissues between DFAT content and resistance of genotypes to $F$. graminearum.

In conclusion, several changes in the cell-wall-bound hydroxycinnamic acid concentrations of silk tissues were observed after inoculation with $F$. graminearum, although these changes were not directly related to genotypic resistance to this fungus. Ester-bound FA decreased, probably due to degradation of hemicellulose by hydrolytic enzymes produced by $F$. graminearum. PCA and DFAT did not diminish after inoculation and, in some cases, appeared to increase above that of the control. However, slight increases of these compounds did not result in delayed $F$. graminearum progression through the silks.

Differential decrease of FA in resistant and susceptible genotypes suggests a possible role of hemicelluloses in $F$. graminearum resistance. The functional role of the hemicellu- 
lose fraction in resistance will be examined more closely in future studies (i.e., the degree of acetylation of arabinoxylan chains in silk could influence the enzymatic degradation by $F$. gramineraum). In the same way, the presence of xylanase inhibitors in the different genotypes needs to be addressed.

\section{MATERIALS AND METHODS}

\section{Experimental design.}

Four AAFC maize inbred lines were used in this study. The inbreds consisted of CO272, one of AAFC's original sources of moderate resistance to $F$. graminearum silk infection; two inbreds with improved silk (CO433 and CO441); and one susceptible check (CO266). These genotypes were grown in two consecutive years, 2007 and 2008, in a split-split plot design with three replicates, at the Central Experimental Farm in Ottawa, Ontario, Canada. The main plot unit consisted of genotypes, the subplot unit consisted of two inoculation treatments (inoculation with a $F$. graminearum macroconidia suspension and inoculation with sterile water as control), and the sub-subplot unit consisted of six harvest times $(0,2,6$, 10 , and 14 days after inoculation for chemical analyses of silk tissues and 70 days after inoculation for evaluation of disease severity on the kernels). Each sub-subplot was a $3.5 \mathrm{~m}$ long row, $0.7 \mathrm{~m}$ apart from consecutive rows, and sown with 15 seeds per row.

\section{Silks inoculation and harvest.}

Three local DON-producing isolates (DAOM 180378, DAOM 194276, and DAOM 212678) of F. graminearum obtained from the National AAFC Fungal Culture Collection were used for inoculum production. Preparation followed a modification of the Bilay's liquid medium as described by Reid and associates (1996). Macroconidia of the three isolates were obtained separately and mixed in equal proportions, reaching a final concentration of $5 \times 10^{5}$ conidia $/ \mathrm{ml}$.

Inbreds were inoculated 5 to 7 days after silk emergence from the ear tip as per Reid and associates (1996). Depending on treatments, $2 \mathrm{ml}$ of $F$. graminearum inoculum or sterile water were injected at a 90-degree angle into the silk channel of the primary ear using an automatic vaccinator. Ten plants per sub-subplot were inoculated. To harvest silks for chemical analysis, exposed silks at the tip of the ear were discarded, ears were cut in half longitudinally, the husk was carefully peeled off, and silks from the upper half of the ear were collected. Samples were stored at $-20^{\circ} \mathrm{C}$ until lyophilized and ground to a fine powder, by hand, using a mortar and pestle.

\section{Ergosterol analysis.}

Ergosterol, a sterol found in fungal membranes but not in animal or plant cells, was measured in the silk samples inoculated with $F$. graminearum in both years as an indicator of fungal biomass. Analyses were carried out as per the methodology of Reid and associates (1999), with slight modifications. Silk tissue $(100 \mathrm{mg}$ ) was placed in culture tubes along with $2 \mathrm{ml}$ of methanol and $0.5 \mathrm{ml}$ of $2 \mathrm{M} \mathrm{NaOH}$. Tubes were tightly closed with teflon-lined caps, placed inside capped 1,000-ml plastic bottles, and irradiated in a microwave oven (Teka, model MW219) at $80 \%$ power $(2,450 \mathrm{MHz}, 800 \mathrm{~W}$ maximum output) for $20 \mathrm{~s}$ and, after approximately $5 \mathrm{~min}$, for an additional $20 \mathrm{~s}$. After cooling, samples were neutralized with $1 \mathrm{M}$ aqueous $\mathrm{HCl}$ and treated with $2 \mathrm{ml}$ of methanol. The samples were partitioned with three times with $4 \mathrm{ml}$ of pentane, and the extracted top pentane layers were combined and evaporated in a rotary evaporator at $50^{\circ} \mathrm{C}$. The extracts were then redissolved in 0.5 $\mathrm{ml}$ of high-performance liquid chromatography (HPLC)-grade methanol and passed through a number 13 nylon syringe filter, $0.45-\mu \mathrm{m}$ pore size, into $2-\mathrm{ml} \mathrm{HPLC}$ vials, and stored at $-20^{\circ} \mathrm{C}$ until HPLC analysis.

HPLC separation was carried out at room temperature by injection of a 50- $\mu$ l sample onto an ACE C18 column (150 by 4 $\mathrm{mm}$ i.d., $5-\mu \mathrm{m}$ particle size) at a flow rate of $2 \mathrm{ml} / \mathrm{min}$ with acetonitrile-methanol (90 to $10 \%$ ) as the eluent under isocratic conditions. The retention time of ergosterol was approximately $8 \mathrm{~min}$. The peak area at the absorption maximum of $282 \mathrm{~nm}$ was used for quantification with an external standard obtained from Sigma-Aldrich (St. Louis).

\section{Extraction and analysis of phenolic fractions.}

Phenolic extraction followed the procedure described by Santiago and associates (2007), with some minor modifications. Freeze-dried sample ( $1 \mathrm{~g}$ ) was extracted in $30 \mathrm{ml}$ of $80 \%$ methanol and homogenized for 30 to $60 \mathrm{~s}$ with a Polytron mixer (Brinkman Instruments, Westbury, NY, U.S.A.). Samples were dark extracted for $1 \mathrm{~h}$ and then centrifuged for $10 \mathrm{~min}$ at $1,000 \times g$. Supernatant was collected and the pellet re-extracted twice with $20 \mathrm{ml}$ of $80 \%$ methanol. The pellets contain the insoluble cell-wall-bound phenolics, and the supernatants contain the soluble phenolics.

The supernatants for soluble phenolic acids were combined and concentrated in a Speed Vac (Savant Instruments, Holbrook, NY, U.S.A.) to $25 \mathrm{ml}$. These aqueous solutions were acidified using $6 \mathrm{~N} \mathrm{HCl}$ to a $\mathrm{pH}$ of 2.0 before extraction with $30 \mathrm{ml}$ of ethyl-acetate. The ethyl-acetate extract was reduced to dryness in a Speed Vac at medium settings without a radiant cover, and the resulting precipitate was resuspended in $3 \mathrm{ml}$ of HPLC-grade methanol. This solution was used to determine free phenolic compounds.

The remaining aqueous solution was divided into two parts. The fraction for soluble glycoside-bound phenolic determination was hydrolyzed in $15 \mathrm{ml}$ of $2 \mathrm{~N} \mathrm{HCl}$ for $1 \mathrm{~h}$ at $4^{\circ} \mathrm{C}$, whereas alkaline hydrolysis for $3 \mathrm{~h}$ in the dark and under a nitrogen atmosphere was used to release the soluble esterbound phenolic compounds. After both digestions, the $\mathrm{pH}$ of the solutions was adjusted to 2.0 and the phenolics were extracted with $30 \mathrm{ml}$ of ethyl acetate. The ethyl acetate extracts were reduced to dryness in a Speed Vac system, and the resulting precipitates were resuspended in $3 \mathrm{ml}$ of HPLC-grade methanol.

The pellet was digested with $20 \mathrm{ml}$ of $2 \mathrm{~N} \mathrm{NaOH}$ and shaken for $4 \mathrm{~h}$ in the dark in a nitrogen atmosphere. Digestion reaction was stopped by adding $6 \mathrm{~N} \mathrm{HCl}$ and the $\mathrm{pH}$ was adjusted to 2.0. Samples were centrifuged as above and supernatant was collected. The pellet was washed twice with $10 \mathrm{ml}$ of distilled water and centrifuged, and supernatants were collected, mixed, and extracted twice with ethyl acetate (50 and $35 \mathrm{ml}$ each). The organic phase was dried using a Speed Vac for $6 \mathrm{~h}$. The extracts were dissolved in $3 \mathrm{ml}$ of HPLC-grade methanol and stored at $-20^{\circ} \mathrm{C}$. All standards and samples were filtered through a $20-\mu \mathrm{m}$ pore poly (tetrafluoroethylene) filter (Chromatographic Specialties, Brockville, Canada) before analysis.

Analyses were performed using a 2690 Waters Separations Module (Waters, Milford, MA, U.S.A.) equipped with a Waters 996 photodiode array detector and a Waters YMC ODSAM narrow-bore column (100 by $2 \mathrm{~mm}$ i.d., 3 - $\mu \mathrm{m}$ particle size). Elution conditions with a mobile phase system of acetonitrile (solvent A) and trifluoroacetic acid (0.05\%) in water $(\mathrm{pH} \mathrm{3.4)}$ (solvent B) were as follows: initial conditions 10:90 (A/B), changing to $30: 70$ in $3.5 \mathrm{~min}$, then to $32: 68$ in $6.5 \mathrm{~min}$, then to 100:0 in $4 \mathrm{~min}$, and then to isocratic elution with 100:0 for 4.5 min, finally returning to the initial conditions in $3 \mathrm{~min}$. The mobile phase flow rate was $0.3 \mathrm{ml} / \mathrm{min}$ and the total analysis time was $21.5 \mathrm{~min}$. The sample injection volume was $4 \mu \mathrm{l}$ and 
the elution profiles were monitored online by UV absorbance at 325, 280, and $254 \mathrm{~nm}$. Retention times were compared with those of freshly prepared standard solutions. Standards of the most common phenolics (caffeic acid, chlorogenic acid, ferulic acid, $p$-coumaric acid, $p$-hydroxybenzoic acid, and vanillic acid) were purchased from Sigma-Aldrich. Identities of ferulic acid dimers were confirmed by comparison with the authentic 5-5' standard or retention time and UV spectra previously published (Waldron et al. 1996).

\section{Evaluation of disease severity.}

At normal grain-harvesting time (70 days after inoculation), 10 ears from the corresponding sub-subplot were evaluated for severity of ear rot infection using a visual rating scale where 1 $=$ no infection and $2=1$ to $3,3=4$ to $10,4=11$ to $25,5=26$ to $50,6=51$ to 75 , and $7=>75 \%$ of kernels exhibit visible symptoms (Reid et al. 1996).

\section{Statistical analysis.}

Combined analyses of variance for disease severity ratings and ergosterol and phenolic concentrations were computed with the PROC GLM procedure of SAS, version 9.1 (SAS Institute, Cary, NC, U.S.A.). Years, replications, and their interactions were considered random. Comparisons of means among genotypes, harvest times, and inoculation treatments were made by Fisher's protected least significant difference.

\section{ACKNOWLEDGMENTS}

This research was supported by the National Plan for Research and Development of Spain (AGL2009-12770/AGR) and the Autonomous Government of Galicia (PGIDIT06TAL40301PR). A. Cao acknowledges funding from the JAE Program of the Spanish Council of Research. R. Santiago acknowledges postdoctoral contract "Isidro Parga Pondal" supported by the Autonomous Government of Galicia.

\section{LITERATURE CITED}

Agger, J., Viksø-Nielsen, A., and Meyer, A. S. 2010. Enzymatic xylose release from pretreated corn bran arabinoxylan: Differential effects of deacetylation and deferuloylation on insoluble and soluble substrate fractions. J. Agric. Food Chem. 58:6141-6148.

Assabgui, R. A., Reid, L. M., Hamilton, R. I., and Arnason, J. T. 1993. Correlation of kernel (E)-ferulic acid content of maize with resistance to Fusarium graminearum. Phytopathology 83:949-953.

Bakan, B., Bily, A. C., Melcion, D., Cahagnier, B., Regnault-Roger, C., Philogène, B. J. R., and Richard-Molard, D. 2003. Possible role of plant phenolics in the production of trichothecenes by Fusarium graminearum strains on different fractions of maize kernels. J. Agric. Food Chem. 5:2826-2831.

Barros-Ríos, J., Malvar, R. A., Jung, H. J., and Santiago, R. 2011. Cell wall composition as a maize defense mechanism against corn borers. Phytochemistry 72:365-371.

Bartolomé, B., Faulds, C. B., Tuohy, M., Hazlewood, G. P., Gilbert, H. J., and Williamson, G. 1995. Influence of different xylanases on the activity of ferulic acid esterase on wheat bran. Biotechnol. Appl. Biochem. 22:65-73.

Beaugrand, J., Crônier, D., Debeire, P., and Chabbert, B. 2010. Arabinoxylan and hydroxycinnamate content of wheat bran in relation to endoxylanase susceptibility. J. Cereal. Sci. 40:223-230.

Beekrum, S., Govinden, R., Padayachee, T., and Odhav, B. 2003. Naturally occurring phenols: A detoxification strategy for fumonisin B1. Food Addit. Contam. 20:490-493.

Biely, P., Leathers, T. D., Cziszarova, M., Vrsanska, M., and Cotta, M. A. 2008 . Endo- $\beta$-1,4-xylanase inhibitors in leaves and roots of germinated maize. J. Cereal Sci. 48:27-32.

Bily, A. C., Reid, L. M., Taylor, J. H., Johnston, D., Malouin, C., Burt, A. J., Bakan, B., Regnault-Roger, C., Pauls, K. P., Arnason, J. T., and Philogène, B. J. R. 2003. Dehydrodimers of ferulic acid in maize grain pericarp and aleurone: Resistance factors to Fusarium graminearum. Phytopathology 93:712-719.

Boutigny, A. L., Barreau, C., Atanasova-Penichon, V., Verdal-Bonnin, M. N., Pinson-Gadais, L., and Richard-Forget, F. 2009. Ferulic acid, an efficient inhibitor of type B trichothecene biosynthesis and Tri gene expression in Fusarium liquid cultures. Mycol. Res. 113:746753.

Bunzel, M. 2010. Chemistry and occurrence of hydroxycinnamate oligomers. Phytochem. Rev. 9:47-64.

de Ascensao, A. R. F. D. C., and Dubery, I. A. 2003. Soluble and cellwall bound phenolics polymers in Musa acuminata roots exposed to elicitors from Fusarium oxysporum f. sp. cubense. Phytochemistry. 63:679-686.

de O. Buanafina, M. M. 2009. Feruloylation in grasses: Current and future perspectives. Mol. Plant 2:861-872.

Eggert, K., Hollamnn, J., Hiller, B., Kruse, H. P., Rawel, H. R., and Pawelzik, E. 2010. Effects of Fusarium infection on the phenolics in emmer and naked barley. J. Agric. Food Chem. 58:3043-3049.

El Modafar, C., Tantaoui, A., and El Boustani, E. 2000. Changes in cell wall-bound phenolic compounds and lignin in roots of date palm cultivars differing in susceptibility to Fusarium oxysporum f. sp. albedinis. J. Phytopathol. 148:405-411.

Grabber, J. H., Hatfield, R. H., and Ralph, J. 1998. Diferulate cross-links impede the enzymatic degradation of non-lignified maize walls. J. Sci. Food Agric. 77:193-200.

Hatfield, R. D., and Marita, J. M. 2010. Enzymatic processes involved in the incorporation of hydroxycinnamates into grass cell walls. Phytochem. Rev. 9:35-45.

Iiyama, K., Lam, T. B. T., and Stone, B. A. 1994. Covalent cross-links in the cell wall. Plant Physiol. 104:315-320.

Ishii, T. 1997. Structure and functions of feruloylated polysaccharides. Plant Sci. 127:111-127.

Kamisaka, S., Takeda, S., Takahashi, K., and Shibata, K. 1990. Diferulic and ferulic acid in the cell wall of Avena coleoptiles-their relationships to mechanical properties of the cell wall. Physiol. Plant. 78:1-7.

Kasenberg, T. R., and Traquair, J. A. 1988. Effects of phenolics on growth of Fusarium oxysporum f. sp. radicis-lycopersici in vitro. Can. J. Bot. 66:1174-1177.

Koehler, B. 1942. Natural mode of entrance of fungi into corn ears and some symptoms than indicate infection. J. Agric. Res. 64:421-442.

Lagaert, S., Belien, T., and Volckaert, G. 2009. Plant cell walls: Protecting the barrier from degradation by microbial enzymes. Semin. Cell Dev. Biol. 20:1064-1073.

Logrieco, A., Mulé, G., Moretti, A., and Bottalico, A. 2002. Toxigenic Fusarium species and mycotoxins associated with maize ear rot in Europe. Eur. J. Plant Pathol. 108:597-609.

Logrieco, A., Bottalico, A., Mulé, G., Moretti, A., and Perrone, G. 2003. Epidemiology of toxigenic fungi and their mycotoxins for some Mediterranean crops. Eur. J. Plant Pathol. 109:645-667.

McKeehen, J. D., Busch, R. H., and Fulcher, R. G. 1999. Evaluation of wheat (Triticum aestivum L.) phenolic acids during grain development and their contribution to Fusarium resistance. J. Agric. Food Chem. 47:1476-1482.

Miller, S. S., Reid, L. M., Butler, G., Winter, S. P., and McGoldrick, N. J. 2003. Long chain alkanes in silk extracts of maize genotypes with varying resistance to Fusarium graminearum. J. Agric. Food Chem. 51:6702-6708.

Miller, S. S., Reid, L. M., and Harris, L. J. 2007. Colonization of maize silks by Fusarium graminearum, the causative organism of Gibberella ear rot. Can. J. Bot. 85:369-376.

Munkvold, G. P. 2003. Epidemiology of Fusarium diseases and their mycotoxins in maize. Eur. J. Plant Pathol. 109:705-713.

Nazareth, S., and Mavinkurve, S. 1986. Degradation of ferulic acid via 4vinylguaiacol by Fusarium solani (Mart.) Sacc. Can. J. Microbiol. 32:494-497.

Pestka, J. J. 2007. Deoxynivalenol: Toxicity, mechanisms and animal health risks. Anim. Feed Sci. Technol. 137:283-298.

Reid, L. M., Bolton, A. T., Hamilton, R. H., Woldemariam, T., and Mather, D. E. 1992a. Effect of silk age on resistance of maize to Fusarium graminearum. Can. J. Plant Pathol. 14:293-298.

Reid, L. M., Mather, D. E., Arnason, J. T., Hamilton, R. I., and Bolton, A. T. 1992b. Changes in phenolic constituents of maize silk infected with Fusarium graminearum. Can. J. Bot. 70:1697-1702.

Reid, L. M., Mather, D.E., Hamilton, R. I., and Bolton, A. T. 1992c. Genotypic differences in the resistance of maize silk to Fusarium graminearum. Can. J. Plant Pathol. 14:211-214.

Reid, L. M., Hamilton, R. I., and Mather, D. E. 1996. Screening maize for resistance to Gibberella ear rot. Agric. Agri-Food Can. Tech. Bull. Publ. 1996-5E.

Reid, L. M., Nicol, R. W., Ouellet, T., Savard, M., Miller, J. D., Young, J. C., Stewart, D. W., and Schaafsma, A. W. 1999. Interaction of Fusarium graminearum and $F$. moniliforme in maize ears: Disease progress, fungal biomass, and mycotoxin accumulation. Phytopathology 89:10281037 
Rosazza, J. P. N., Huang, Z., Dostal, L., Volm, T., and Rousseau, B. 1995. Biocatalytic transformation of ferulic acid: An abundant natural product. J. Ind. Microbiol. 15:457-471.

Samapundo, S., De Meulenaer, B., Osei-Nimoh, D., Lamboni, Y., Debevere and J., Devlieghere, F. 2007. Can phenolic compounds be used for the protection of corn from fungal invasion and mycotoxin contamination during storage? Food Microbiol. 24:465-473.

Santiago, R., and Malvar, R. A. 2010. Role of dehydrodiferulates in maize resistance to pests and diseases. Int. J. Mol. Sci. 11:691-703

Santiago, R., Butrón, A., Arnason, J. T., Reid, L. M., Souto, X. C., and Malvar, R. A. 2006a. Putative role of pith cell wall phenylpropanoids in Sesamia nonagrioides (Lepidoptera: Noctuidae) resistance. J. Agric. Food Chem. 54:2274-2279.

Santiago, R., Butrón, A., Reid, L. M., Arnason, J. T., Sandoya, G., Souto, X. C., and Malvar, R. A. 2006b. Diferulate content of maize sheaths is associated with resistance to the Mediterranean corn borer Sesamia nonagrioides (Lepidoptera: Noctuidae). J. Agric. Food Chem. 54:9140 9144.

Santiago, R., Reid, L. M., Arnason, J. T., Zhu, X. Y., Martínez, N., and Malvar, R. A. 2007. Phenolics in maize genotypes differering in susceptibility to Gibberella stalk rot (Fusarium graminearum Schwabe). J.
Agric. Food Chem. 55:5186-5193.

Santiago, R., de Armas, R., Fontaniella, B., Vicente, C., and Legaz, M. E. 2009. Changes in soluble and cell-wall bound hydroxycinnamic and hydroxybenzoic acids in sugarcane cultivars inoculated with Sporisorium scitamineum sporidia. Eur. J. Plant Pathol. 124:439-450.

Sella Kapu, N. U., and Cosgrove, D. J. 2010. Changes in growth and cell wall extensibility of maize silks following pollination. J. Exp. Bot. 61:4097- 4107.

Sutton, J. C. 1982. Epidemiology of wheat head blight and maize ear rot caused by Fusarium graminearum. Can. J. Plant Pathol. 4:195-209.

Wakabayashi, K., Hoson, T., and Kamisaka, S. 1997. Abscisic acid suppresses the increases in cell wall-bound ferulic and diferulic acid levels in dark-grown wheat (Triticum aestivum L.) coleoptiles. Plant Cell Physiol. 38:811-817.

Waldron, K. W., Parr, A. J., Ng, A., Ralph, J., and Williamson, G. 1996. Cell wall esterified phenolic dimers: Identification and quantification by reversed phase high performance liquid chromatography and diode array detection. Phytochem. Anal. 7:305-312.

Walter, S., Nicholson, P., and Doohan, F. M. 2010. Action and reaction of host and pathogen during Fusarium head blight disease. New Phytol. 185:54-66. 